\title{
High FDG activity in focal fat necrosis: a pitfall in interpretation of post treatment PET/CT in patients with non-Hodgkin lymphoma
}

Short title: FDG-avid fat necrosis in NHL

Authors:

Dr Raghava Kashyap ${ }^{1}$, Associate Prof Eddie Lau ${ }^{1,4}$, Dr Anupkumar George ${ }^{2}$, Prof John F. Seymour $^{2,4}$, Dr Stephen Lade ${ }^{3,4}$, Prof Rodney J. Hicks ${ }^{1,4}$, Dr Michael S. Hofman ${ }^{1,4}$

\section{Affiliation:}

${ }^{1}$ Centre for Cancer Imaging, ${ }^{2}$ Departments of Haematology and ${ }^{3}$ Pathology, Peter MacCallum Cancer Centre, Melbourne, Australia. ${ }^{4}$ Departments of Medicine, Radiology and Pathology, University of Melbourne, Australia

\section{Corresponding Author:}

Dr Michael Hofman, MBBS (Hons), FRACP

Consultant Physician in Nuclear Medicine

Email: michael.hofman@petermac.org

Department of Cancer Imaging, Peter MacCallum Cancer Centre, St Andrews Place

Melbourne, Australia 3002.

Phone: +61396561852

Fax: +61396561826

\section{First Author:}

Dr Raghava Kashyap, MBBS, MD (Nuclear Medicine)

Research Fellow

Email: kashyapkr@gmail.com

c/o Department of Cancer Imaging, Peter MacCallum Cancer Centre, St Andrews Place Melbourne, Australia 3002.

Word counts:

Abstract: 150 words | Manuscript: 1762 words 
Abstract:

PET/CT has a major role in lymphoma imaging but glycolytic activity in inflammatory processes can reduce specificity. The study evaluates restaging PET/CT findings in patients with non-Hodgkin lymphoma (NHL) and fat necrosis. Methods: We identified 16 patients from 8819 restaging FDG PET/CT scans with biopsy proven fat necrosis or suspicion on PET/CT. Results: All patients had NHL and demonstrated focal FDG-avid nodular change on CT with density higher than fat but lower than soft tissue. Histological confirmation was obtained in 8 patients, with high GLUT-1 staining between necrotic tissue and organising fat necrosis evident. Uptake resolved in 4 patients, and 4 remain on surveillance without relapse. Conclusion: Although rare, identification of fat necrosis in patients with a solitary FDG-avid nodule after therapy is important and may avoid unnecessary interventions or treatment. Specific features on CT aid identification, whilst follow-up imaging can be helpful as the metabolic abnormality regresses with time.

Key Words: PET, Non-Hodgkin Lymphoma, Fat necrosis, False positive 


\section{INTRODUCTION}

F-18 Fluorodeoxyglucose (FDG) positron emission tomography combined with computer tomography (PET/CT) has become an integral component of patient management in lymphoma [1-3]. Compared to conventional imaging advantages include high tumor to background contrast, high reproducibility[4] and the ability to assess response before anatomical changes or exclude active disease in patients with residual masses. Although it is very sensitive, FDG uptake is not specific for malignant processes. There are several non-lymphomatous physiological and pathological causes for FDG uptake[5-8] and a thorough knowledge of these processes and their imaging features are important to limit unnecessary interventions. Some of the physiological causes include metabolic activity associated with brown adipose tissue, muscle, bowel and female genital organs [5]. Similarly, reactive lymph node changes, rebound thymic hyperplasia, post radiotherapy pneumonitis and inflammatory diseases also show increased FDG uptake [5-7]. Diffuse increase in bone marrow and splenic uptake can also be seen after administration of haematopoietic growth factors, whilst focal bony involvement can be attributable to bony remodelling rather than active disease $[9,10]$. We discuss a series of patients with non-Hodgkin lymphoma (NHL) and high focal FDG uptake following treatment associated with presumed or proven fat necrosis that could present a pitfall in interpretation of PET/CT.

\section{MATERIAL AND METHODS}

We retrospectively analysed cases with NHL that were referred for FDG PET/CT after treatment in whom "fat necrosis" was suspected on imaging, or its presence was proven histopathologically. Cases were identified by searching PET/CT reports from 1/2006 to $10 / 2012$ performed for lymphoma restaging containing the words "fat necrosis" or "mesenteric panniculitis" or similar sounding words. Haematologists were also surveyed for known cases of histopathologically proven fat necrosis to identify patients who were not identified prospectively on PET/CT. Details of patient characteristics, diagnosis, treatment, PET findings and follow-up are described in Table 1. This research was approved by the Centre for Cancer Imaging, Peter 
MacCallum Cancer Centre, and constituted a clinical audit not requiring ethics committee approval according to institutional guidelines.

PET/CT imaging was performed on a combined PET/CT scanner; either a Discovery 690 or STE (GE Medical Medical Systems, Milwaukee, USA) or a Biograph 64 (Siemens Medical Systems, USA) scanner. Dose of FDG was weight adjusted using $3.6 \mathrm{MBq} / \mathrm{kg}$ for the Discovery 690 and Biograph 64, and $4.2 \mathrm{MBq} / \mathrm{kg}$ for Discovery STE; the actual mean administered dose was $256 \mathrm{MBq}$, range $144-314 \mathrm{MBq}$. Mean uptake time was 68 minutes (range 60-81). Low-dose contemporaneous CT was performed on all patients without intravenous or oral contrast. The baseline and index PET/CT and available contrast enhanced CT studies were reviewed to identify any patterns associated with fat necrosis, including measurement of standardised uptake value (SUVmax) and Hounsfield unit (HU).

Histopathologic review of the positive specimens was performed by a single histopathologist (SL). Immunohistochemistry was performed using anti-GLUT-1 monoclonal antibody (Thermo Scientific, clone SPM498) and routine staining protocols on the Ventana platform (Roche, Basel, Switzerland),

\section{RESULTS}

8819 FDG PET/CT scans were performed in 3342 patients for lymphoma restaging during the study period. 16 patients with fat necrosis $($ Female $=7$, Male $=9$ ) were identified with a median age of 59 years (range 26-71). Two of these patients had well-controlled diabetes mellitus but none had lymphoma-related symptoms at the time of the scan. Thirteen had histologically aggressive NHL, while 3 patients had follicular lymphoma. Five patients had received radiotherapy to the site at which PET abnormality was detected. The median duration of the PET scan from the last treatment was 8 (range 4-40) weeks. All these studies showed a complete metabolic response (CMR) at all other previous sites of disease except for the solitary abnormal focus. 8 patients proceeded to biopsy which confirmed fat necrosis. 
PET/CT findings: The foci of fat necrosis were most commonly seen in the mesentery $(n=14)$, though breast and mediastinal fat were sites in one case each. Prior to initiation of treatment for the NHL, bulky disease $(>10 \mathrm{~cm}$ lesion diameter) was seen in 5 patients while mesenteric vessel encasement was noted in 6 cases. The residual metabolically-active lesion measured an average maximum diameter of 20 (range 15-28) mm with a mean SUVmax of 6.4 (range 3.8-13.2). The lesions had smooth or ill defined borders on the contemporaneous CT with surrounding fat stranding in all cases (Fig. 2c). The mean radiographic density of the lesions was 12.5 HU, which was lower than density measured along the psoas muscle (46.1 HU) for comparison as a soft tissue density $(\mathrm{p}<0.05)$. In 3 patients the lesions demonstrated an area of central fat density surrounded by a soft tissue density giving a "doughnut" appearance (Fig. 3). All the patients with the abnormal foci in the mesentery showed features of mesenteric stranding and nodules on their pre-treatment imaging.

\section{Follow up:}

Follow up of a minimum of 6 months was available for 12 patients. Of these 12 patients 2 had surgical excision of the suspected lesions and confirmation on subsequent histological examination. No residual lesions were seen on post-surgical PET/CT scans in these two patients. A further six patients had biopsy confirmation, with follow-up PET/CT demonstrating complete resolution in 3 (at 9, 10 and 12 months) and partial resolution in 3 (commencing as early as 1 month, but persisting up to a year). Four patients are undergoing surveillance beyond 6 months without documented recurrence.

\section{Histopathology:}

Specimens from 5 of 8 patients with histologically confirmed fat necrosis were available for central review. Histology demonstrated typical features of fat necrosis with macrophage infiltration, fibrosis and sparse mature chronic inflammatory cells. There was no evidence of recurrent lymphoma in any of the samples. Some of the cases showed discreet areas of fibrosis. GLUT-1 immunohistochemistry showed a prominent peri-necrotic staining pattern but no staining in viable organising tissue or the necrotic area (see Fig 4). 


\section{DISCUSSION}

FDG PET/CT has become a standard of care for restaging in patients with aggressive NHL. It has a very high negative predictive value and a moderate positive predictive value in detection of residual disease[1]. Several physiological and inflammatory nonlymphomatous conditions also cause FDG uptake reducing its specificity and necessitating skill in interpretation. Understanding this has become more relevant in recent years as consensus criteria for reporting are being established[11].

Fat necrosis mimicking residual disease has been described in isolated case reports $[12,13]$. This was a rare finding in this series occurring in $0.2 \%$ of total scans or $0.5 \%$ of patients scanned for restaging lymphoma. It is likely other cases were not identified so the true incidence of fat necrosis is likely to be higher. All identified patients had biopsy proven NHL and were free of lymphoma-related symptoms at the time of imaging. In most of the cases the focus of fat necrosis was identified within a year of the last treatment (chemotherapy or radiotherapy). A characteristic "doughnut sign" of fat necrosis was only seen in 3 patients [14]. Given that the intensity of uptake was in the range typical for residual/recurrent lymphoma, the presence of moderate to intense FDG-avidity might lead an inexperienced reader to report it as disease recurrence. We have identified some radiological features which assist in determining that fat necrosis is likely. Though the lesions appear similar to nodal lesions, they have a lower density than soft tissue which can be confirmed by measurement of the Hounsfield units. Another notable feature is that all the patients showed complete response at all other sites of disease. Interestingly, in 9 cases (56\%), the area of fat necrosis was not located at sites of baseline disease. To the best of our knowledge this is the first description of FDG PET findings in histologically confirmed supradiaphragmatic fat necrosis (one in neck and another in breast in our series) in the literature.

All the patients with mesenteric fat necrosis showed features of mesenteric stranding and nodules on the baseline study. These findings might be considered to be due to mesenteric panniculitis (MP) but the lack of FDG avidity at baseline might suggest an alternative aetiology such as venous and lymphatic congestion. The radiological findings in MP include a "misty" appearance of the mesentery with a hyperdense stripe of variable thickness surrounding the area of mesenteric changes (or mass) separating it from normal adjacent mesentery $[15,16]$. Nodular changes may also be 
noted in MP. The density of these areas was lower than soft tissue but more than uninvolved fat. Daskalogiannaki et al[15] reported features of MP in $0.6 \%$ of patients undergoing CT, with $69 \%$ having an associated malignancy such as lymphoma, ovarian cancer or colonic cancer. However, Canyigit et al.[17] described MP more frequently with benign disorders. In a retrospective series of 19 patients with MP who had underwent FDG PET/CT, Zissin et al [19] found that all patients with FDG-avid nodules had tumoural involvement whilst benign MP did not show FDG uptake. In our series, mesenteric stranding was noted in 11 patients while non-FDG avid nodular changes on baseline study were seen in 7. Finally, Joerger et al. [18] reported CT features of MP to be present in $9 \%$ of patients with NHL.

In most patients in our cohort who were observed, the abnormal FDG uptake either completely or partially resolved on follow-up scans, confirming the non-progressive and self-limiting nature of the process. The metabolic activity, however, can persist for as long as 12 months. One of the limitations of our study is that although the patients did not have recurrent disease or progression of the lesions, the period of follow up was relatively short in some of the patients. The aetiology of fat necrosis is often unclear, although causes such as infection, trauma and ischemia have been suggested. In our series, only one patient had surgical debulking, which could potentially have led to fat necrosis from intra-operative trauma. Mesenteric ischemia is a possible contributor to the development of fat necrosis in our series, with encasement of mesenteric vessels and/or bulky mesenteric nodal involvement seen in 8 cases. Ischemia from post-treatment radiation fibrosis involving the mesenteric vessels may also be a contributory factor, though only a minority of the patients underwent radiation (5 patients).

\section{CONCLUSION}

In conclusion, fat necrosis is a potential cause for non-lymphomatous uptake on FDG PET/CT in patients with NHL after treatment. The occurrence of fat necrosis appears to be related to features of MP on the pre-treatment PET/CT scan and could be a result of trauma, ischemia or vascular compromise from either the disease or its treatment. Although rare, fat necrosis should be included in the differential diagnosis for causes for solitary FDG-avid lesions after therapy in NHL. Understanding the 
clinical setting and imaging features described should assist in recognition of this potential pitfall and avoid unnecessary interventions or inappropriate treatment.

\section{ACKNOWLEDGMENT}

We would like to thank Dr M Dickinson, Professor M Prince and Associate Professor D Ritchie for contributing cases. Dr R Kashyap was supported by Endeavour Awards, a venture of Austraining International in partnership with the Government of Australia.

\section{CONFLICT OF INTEREST}

The authors declare that they have no conflict of interest. 


\section{REFERENCES}

1. Baba S, Abe K, Isoda T, Maruoka Y, Sasaki M, Honda H. Impact of FDGPET/CT in the management of lymphoma. Annals of nuclear medicine. 2011;25:70116. doi:10.1007/s12149-011-0549-0.

2. MacManus MP, Seymour JF, Hicks RJ. Overview of early response assessment in lymphoma with FDG-PET. Cancer imaging : the official publication of the International Cancer Imaging Society. 2007;7:10-8. doi:10.1102/14707330.2007.0004.

3. Hicks RJ, Mac Manus MP, Seymour JF. Initial staging of lymphoma with positron emission tomography and computed tomography. Seminars in nuclear medicine. 2005;35:165-75. doi:10.1053/j.semnuclmed.2005.02.003.

4. Hofman MS, Smeeton NC, Rankin SC, Nunan T, O'Doherty MJ. Observer variation in interpreting 18F-FDG PET/CT findings for lymphoma staging. Journal of nuclear medicine : official publication, Society of Nuclear Medicine. 2009;50:1594-7. doi:10.2967/jnumed.109.064121.

5. McDermott S, Skehan SJ. Whole body imaging in the abdominal cancer patient: pitfalls of PET-CT. Abdominal imaging. 2010;35:55-69. doi:10.1007/s00261008-9493-4.

6. De Gaetano AM, Calcagni ML, Rufini V, Valentini AL, Gui B, Giordano A, et al. Imaging of gynecologic malignancies with FDG PET-CT: case examples, physiologic activity, and pitfalls. Abdominal imaging. 2009;34:696-711. doi:10.1007/s00261-008-9457-8.

7. Kapoor V, Fukui MB, McCook BM. Role of 18FFDG PET/CT in the treatment of head and neck cancers: posttherapy evaluation and pitfalls. AJR American journal of roentgenology. 2005;184:589-97.

8. Guy SD, Tramontana AR, Worth LJ, Lau E, Hicks RJ, Seymour JF, et al. Use of FDG PET/CT for investigation of febrile neutropenia: evaluation in high-risk cancer patients. European journal of nuclear medicine and molecular imaging. 2012;39:1348-55. doi:10.1007/s00259-012-2143-7.

9. Hollinger EF, Alibazoglu H, Ali A, Green A, Lamonica G. Hematopoietic cytokine-mediated FDG uptake simulates the appearance of diffuse metastatic disease on whole-body PET imaging. Clinical nuclear medicine. 1998;23:93-8.

10. Ng AP, Wirth A, Seymour JF, Lee M, Hogg A, Januszewicz H, et al. Early therapeutic response assessment by (18)FDG-positron emission tomography during chemotherapy in patients with diffuse large B-cell lymphoma: isolated residual positivity involving bone is not usually a predictor of subsequent treatment failure. Leukemia \& lymphoma. 2007;48:596-600. doi:10.1080/10428190601099965.

11. Meignan M, Gallamini A, Itti E, Barrington S, Haioun C, Polliack A. Report on the Third International Workshop on Interim Positron Emission Tomography in Lymphoma held in Menton, France, 26-27 September 2011 and Menton 2011 consensus. Leukemia \& lymphoma. 2012;53:1876-81. doi:10.3109/10428194.2012.677535.

12. Adejolu M, Huo L, Rohren E, Santiago L, Yang WT. False-positive lesions mimicking breast cancer on FDG PET and PET/CT. AJR American journal of roentgenology. 2012;198:W304-14. doi:10.2214/AJR.11.7130.

13. Belakhlef A, Jani C, Church C, Fraser R, Lakhanpal S. Fat necrosis mimicking B-cell lymphoma: a PET/CT and FDG study. Clinical nuclear medicine. 2008;33:2712. doi:10.1097/RLU.0b013e3181662bbf. 
14. Singh AK, Gervais DA, Lee P, Westra S, Hahn PF, Novelline RA, et al. Omental infarct: CT imaging features. Abdominal imaging. 2006;31:549-54. doi:10.1007/s00261-005-0251-6.

15. Daskalogiannaki M, Voloudaki A, Prassopoulos P, Magkanas E, Stefanaki K, Apostolaki E, et al. CT evaluation of mesenteric panniculitis: prevalence and associated diseases. AJR American journal of roentgenology. 2000;174:427-31.

16. Horton KM, Lawler LP, Fishman EK. CT findings in sclerosing mesenteritis (panniculitis): spectrum of disease. Radiographics : a review publication of the Radiological Society of North America, Inc. 2003;23:1561-7. doi:10.1148/rg.1103035010.

17. Canyigit M, Koksal A, Akgoz A, Kara T, Sarisahin M, Akhan O. Multidetector-row computed tomography findings of sclerosing mesenteritis with associated diseases and its prevalence. Japanese journal of radiology. 2011;29:495502. doi:10.1007/s11604-011-0587-5.

18. Joerger M, Nuessli DF, Henz S, Zaunbauer W, Cerny T, Cogliatti SB, et al. CT-diagnosed mesenteric alterations in patients with non-Hodgkin's lymphoma: a population-based study. Onkologie. 2008;31:514-9. doi:10.1159/000151624.

19. Zissin R, Metser U, Hain D, Even-Sapir E. Mesenteric panniculitis in oncologic patients: PET-CT findings. The British journal of radiology. 2006;79:3743. doi:10.1259/bjr/29320216. 


\section{FIGURE LEGENDS}

A

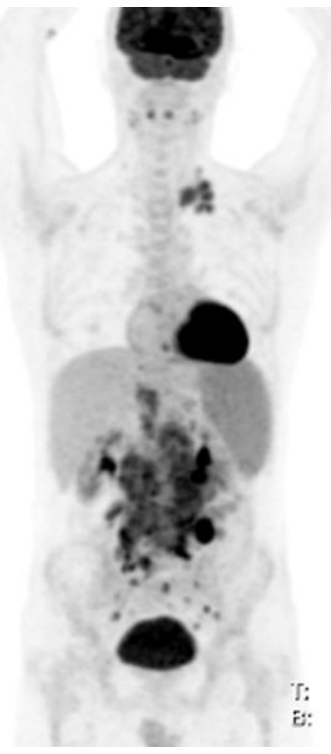

B

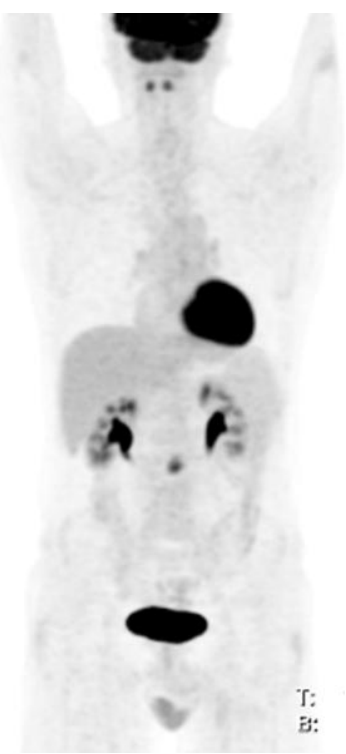

C

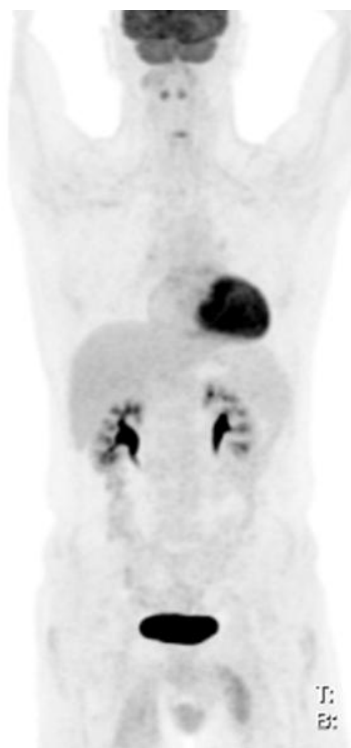

Fig. 1: (a) - Maximum intensity projection series (patient 1) showing baseline PET with abdominopelvic and cervical nodal disease, (b) post treatment PET showing complete response at all sites except for a solitary focus in the abdomen which resolved following laparotomy and excision (c). Histopathology confirmed focal fat necrosis. 


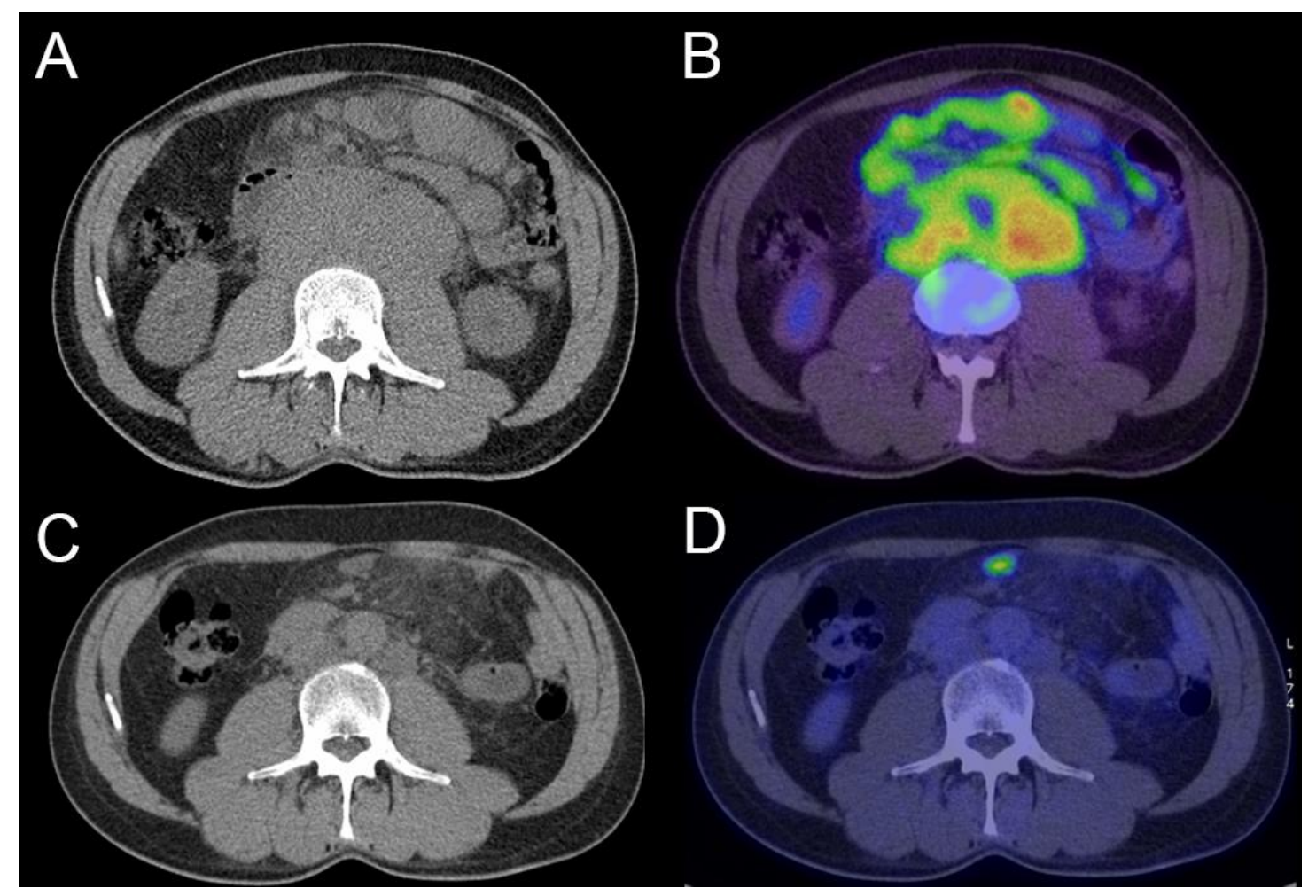

Fig. 2: Transaxial images (patient 1) of baseline CT (a) and fused PET/CT (b) showing retroperitoneal and mesenteric disease. The follow up CT (c) and fused PET/CT (d) images showing an FDG-avid ill-defined lesion in the mesentery with complete metabolic response elsewhere. Note mesenteric stranding on both pre- and post-treatment CT images. 

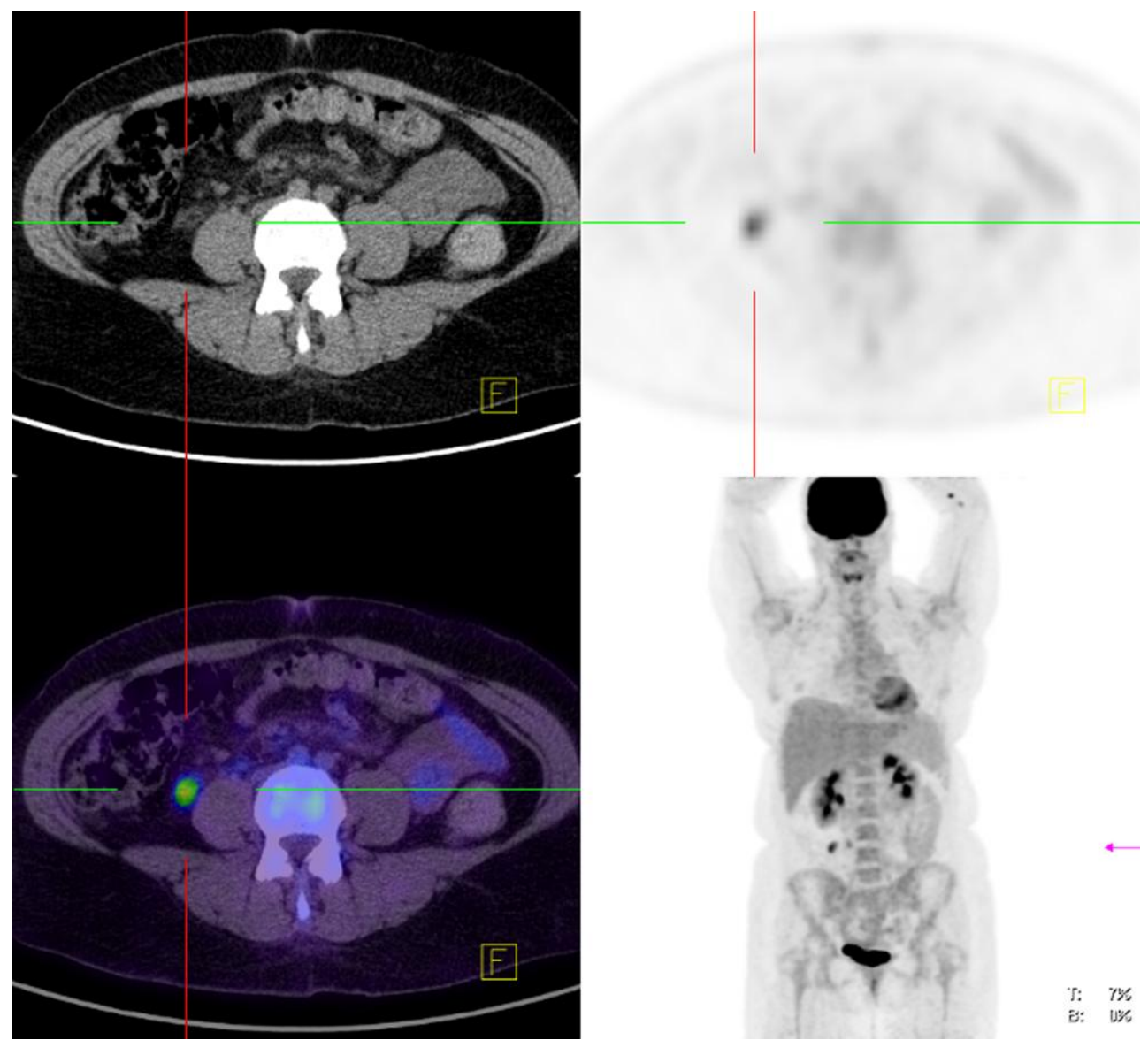

Fig. 3: Images (patient 12) showing doughnut appearance of the focus of fat necrosis. 


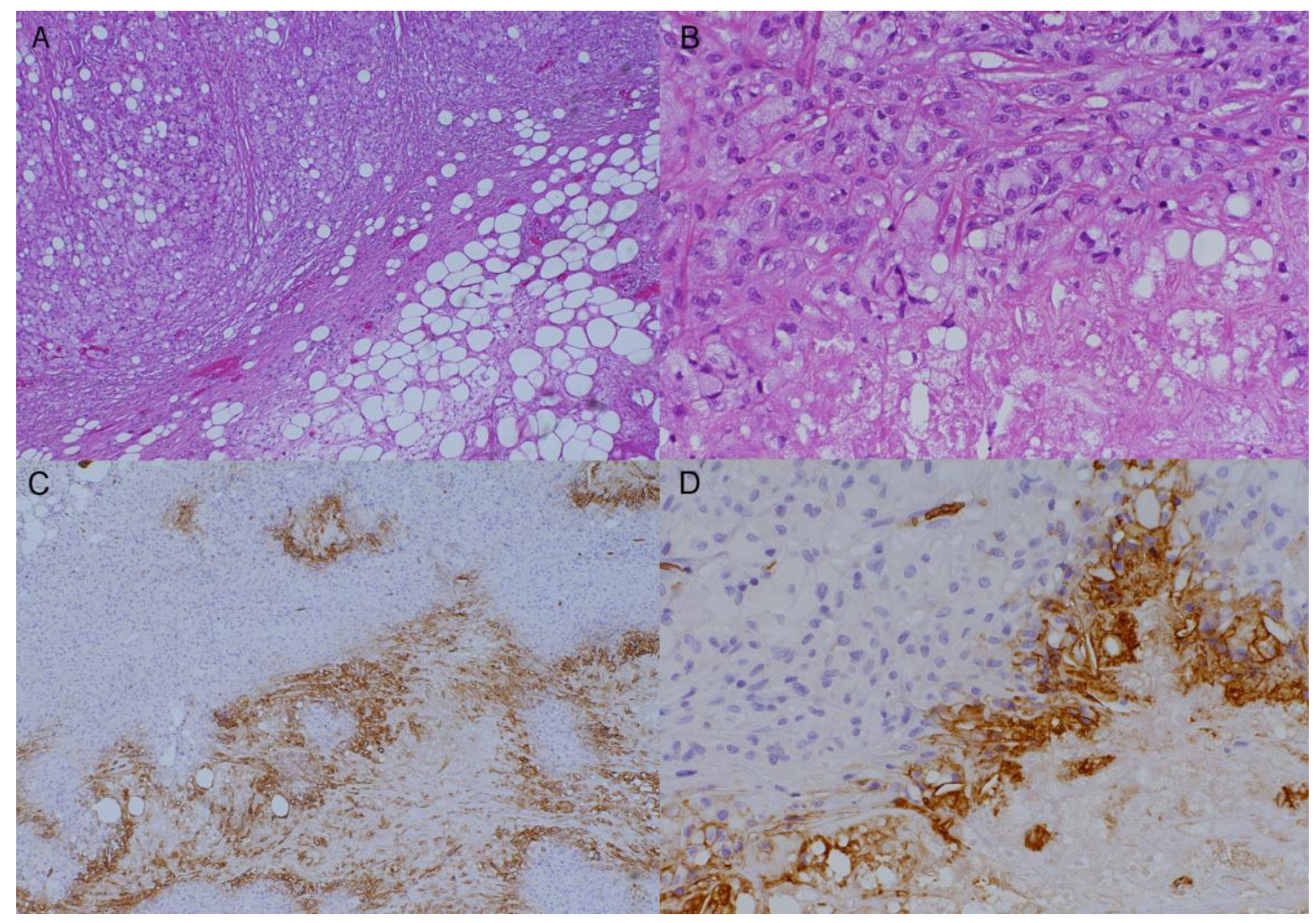

Fig. 4: (a) Hematoxylin and eosin stain (H\&E) section X40 magnification demonstrating organising fat necrosis. (b) X200 magnification demonstrating viable organising fat necrosis in the top portion and necrosis in the bottom portion. (c) X40 magnification demonstrating GLUT-1 immunoperoxidase staining predominantly at the junction of necrotic and viable tissue. (d) X200 magnification. 
TABLE 1: Summary of patient demographics, prior treatment and imaging findings

\begin{tabular}{|c|c|c|c|c|c|c|c|c|c|c|c|c|}
\hline & $\begin{array}{l}\text { Age } \\
\text { Gen } \\
\text { der }\end{array}$ & Diagnosis & Stage & Treatment & $\begin{array}{l}\text { Time of } \\
\text { imaging } \\
\text { from last } \\
\text { treatment } \\
\text { (months) }\end{array}$ & SUVmax & $\begin{array}{l}\text { Size } \\
(\mathbf{m m})\end{array}$ & $\begin{array}{l}\text { Density } \\
\text { of lesion } \\
(\mathrm{HU})\end{array}$ & $\begin{array}{l}\text { Reference } \\
\text { (Psoas HU) }\end{array}$ & $\begin{array}{l}\text { Site of fat } \\
\text { necrosis }\end{array}$ & $\begin{array}{l}\text { At site of original } \\
\text { disease }\end{array}$ & Follow up \\
\hline 1 & $57 \mathrm{M}$ & $\begin{array}{l}\text { FL Grade } 3 \\
\text { with } \\
\text { transformati } \\
\text { on } \\
\end{array}$ & IV-Bulky & R-CHOP & 4 & 7.1 & 24 & 7.8 & 47 & Mesentery & + & $\begin{array}{l}\text { Biopsy + } \\
\text { Resolution } \\
\text { on F/U PET }\end{array}$ \\
\hline 2 & $71 \mathrm{~F}$ & DLBCL & III & R-CHOP & 1 & 13.2 & 23 & 7 & 43 & Mesentery & - & On F/U \\
\hline 3 & $62 \mathrm{~F}$ & $\begin{array}{l}\text { Peripheral T } \\
\text { Cell } \\
\text { Lymphoma }\end{array}$ & III & CVAD & 1 & 3.8 & 26 & -4 & 48 & Breast & + & $\begin{array}{l}\text { Biopsy } \\
\text { proven . } \\
\text { Resolved on } \\
\text { F/U }\end{array}$ \\
\hline 4 & $68 \mathrm{M}$ & DLBCL & III & $\begin{array}{l}\text { R-CHOP } \\
\text { BCNU }\end{array}$ & 3 & 4.5 & 15 & -36 & 45 & Mesentery & - & On F/U \\
\hline 5 & $68 \mathrm{~F}$ & FL & IV & R-CHOP & 1 & 7.7 & 24 & 4 & 43 & Mesentery & - & $\begin{array}{l}\text { Resolved on } \\
\text { F/U }\end{array}$ \\
\hline 6 & $76 \mathrm{~F}$ & $\begin{array}{l}\text { CLL } \\
\text { (Richter } \\
\text { transformati } \\
\text { on) }\end{array}$ & III & R-CHOP & 1 & 9.7 & 14 & -34 & 43 & Mesentery & - & $\begin{array}{l}\text { Resolved on } \\
\text { F/U }\end{array}$ \\
\hline 7 & $60 \mathrm{M}$ & $\mathrm{FL}$ & IV & $\begin{array}{l}\text { CVP, } \\
\text { Chlorambucil, } \\
\text { Radioimmunothe } \\
\text { rapy }\end{array}$ & 3 & $\mathrm{n} / \mathrm{a}$ & 16 & -57 & 55 & Mesentery & - & $\begin{array}{l}\text { Resolved on } \\
\text { F/U }\end{array}$ \\
\hline 8 & $51 \mathrm{M}$ & DLBCL & II & $\mathrm{R}-\mathrm{CHOP}$ & 5 & 7 & 15 & -14 & 43 & Mesentery & - & On F/U \\
\hline 9 & $59 \mathrm{~F}$ & DLBCL & IV & $\begin{array}{l}\text { R-CHOP } \\
\text { RT }\end{array}$ & 10 & 3.6 & 17 & 10 & 56 & Mesentery & - & $\begin{array}{l}\text { Confirmed } \\
\text { after } \\
\text { laparotomy } \\
\text { and excision }\end{array}$ \\
\hline
\end{tabular}




\begin{tabular}{|l|l|l|l|l|l|l|l|l|l|l|l|l|}
\hline 10 & $71 \mathrm{M}$ & FL & II & RT & 2 & 4.5 & 20 & -36 & 40 & Mesentery & - \\
\hline 11 & $47 \mathrm{M}$ & DLBCL & III-Bulky & R-CHOP, RT & 12 & 3.7 & 28 & -15 & 53 & Mesentery & + \\
\hline 12 & $61 \mathrm{M}$ & DLBCL & I & $\begin{array}{l}\text { Surgical } \\
\text { debulking, } \\
\text { CHOP }\end{array}$ & 2 & $\mathrm{n} / \mathrm{a}$ & $\mathrm{n} / \mathrm{a}$ & $\mathrm{n} / \mathrm{a}$ & $\mathrm{n} / \mathrm{a}$ & $\begin{array}{l}\text { Biopsy was } \\
\text { negative for } \\
\text { recurrence. } \\
\text { Resolved on } \\
\text { F/U }\end{array}$ \\
\hline 13 & $40 \mathrm{~F}$ & Burkitt & III-Bulky & CVAD & 2 & 6.4 & 22 & -40 & 45 & Mesentery & + \\
proven & $\begin{array}{l}\text { Biopsy } \\
\text { proven }\end{array}$ \\
\hline 14 & $62 \mathrm{M}$ & DLBCL & III & R-CHOP, RT & 1 & 5.6 & 25 & 5 & 47 & Mesentery & - \\
\hline 15 & $26 \mathrm{G}$ & DLBCL & II-Bulky & EPOCH, R-ICE & 1 & 6.6 & 26 & 23 & 40 & Mediastinum & + \\
\hline 16 & $62 \mathrm{M}$ & DLBCL & IVBulky & R-CHOP, RT & 3 & $\mathrm{n} / \mathrm{a}$ & 16 & -0.8 & 44 & $\begin{array}{l}\text { Biopsy PET } \\
\text { proven }\end{array}$ \\
\hline
\end{tabular}

FL: follicular lymphoma; DLBCL: diffuse large B cell lymphoma; CLL: chronic lymphocytic leukemia; RT: radiotherapy; R-CHOP: Rituximab, Cyclophosphamide, Doxorubicin, Vincristine, Prednisolone; CVAD: Cyclophosphamide, Vincristine, Doxorubicin, Dexamethasone; EPOCH: etoposide, vincristine, doxorubicin, cyclophosphamide, and prednisone; R-ICE: Rituximab, ifosfamide, carboplatin, etoposide 